\title{
PURE AORTIC STENOSIS
}

\author{
BY \\ G. A. KILOH \\ From the Institute of Cardiology, National Heart Hospital \\ Received June 8, 1949
}

This paper is concerned with cases of pure aortic stenosis occurring in subjects under the age of 50 years. Many papers have been written since Monckeberg contributed the first systematic investigation of aortic stenosis in 1904.- It has been studied from many aspects, but most authors have been concerned with aortic stenosis of any degree, accompanied or not by incompetence, and irrespective of the age of the patient. Exception to this general rule has been provided by Gallavardin $(1909,1921,1936)$ who contributed three papers on the subject of pure aortic stenosis, though many of his cases were not pure in the strictest sense, as there was accompanying incompetence, but only of such a degree that it could not be suspected by examination of the peripheral circulation or blood pressure. Gallavardin's conclusions have received little consideration from the British and American schools. It is widely held that pure aortic stenosis is rare and it is one of the objects of this paper to show that this idea is exaggerated. The fact that stenosis of the aortic valve can be pure should not be unacceptable when pulmonary stenosis is generally so. Pure aortic stenosis, particularly when it occurs in young people, is uncommon (though not rare) and easily overlooked.

\section{Clinical Material}

For purposes of this paper all cases of aortic stenosis without evidence of incompetence were studied, regardless of whether other valve lesions were present, provided the subject was under 50 years of age. In addition to the fifteen cases seen personally, the more recent records of the National Heart Hospital were examined and the notes of a further twelve cases abstracted. It has not been found possible to complete the findings in any case by autopsy.

The main points in the history of these cases are summarized in Table $I$. The fact that twenty of the twenty-seven cases were males is in accordance with other lesions of the aorta and aortic valve. The age incidence was evenly distributed from the age of five years upwards. Most patients gave a history of known or suspected heart disease of many years duration, in twelve over ten years and in eight of these over twenty years. In spite of this only eight presented with symptoms, and these facts agree with the recognized benign nature of aortic stenosis and the consequent late development of symptoms. Of eight patients who were eligible, five served for long periods in the recent war, this also indicating the ease with which the condition may be overlooked. Of the twenty-seven cases, twenty-six denied any history of a rheumatic illness. The remaining one suggested that he had had rheumatic fever in childhood, but interrogation of the parents made this unlikely - an important fact for further consideration.

The physical signs displayed in the fifteen cases seen personally are summarized in Table II. In most cases the cardiac impulse was of normal character, so that palpation confined to the mitral area would not lead to any suspicion of heart disease. In one only (14) was the cardiac impulse certainly abnormal, though four others were suspicious because of its forcible character. Even so a systolic thrill was present in the aortic area in every case, though in five it was only just appreciated with the patient leaning forward, after exertion and in full expiration. That such a thrill could be 
TABLE I

Age Incidence And History in Pure Aortic Stenosis (A.S.)

\begin{tabular}{l|c|c|c|c|c|c|c}
\hline Case No. & Sex & $\begin{array}{c}\text { Present } \\
\text { age }\end{array}$ & $\begin{array}{c}\text { Age A.S. } \\
\text { confirmed }\end{array}$ & $\begin{array}{c}\text { Age heart } \\
\text { suspected }\end{array}$ & $\begin{array}{c}\text { Length of } \\
\text { history } \\
\text { (years) }\end{array}$ & $\begin{array}{c}\text { Mode of } \\
\text { discovery }\end{array}$ & $\begin{array}{c}\text { Army service } \\
\text { (years) }\end{array}$ \\
\hline
\end{tabular}

Cases seen personally

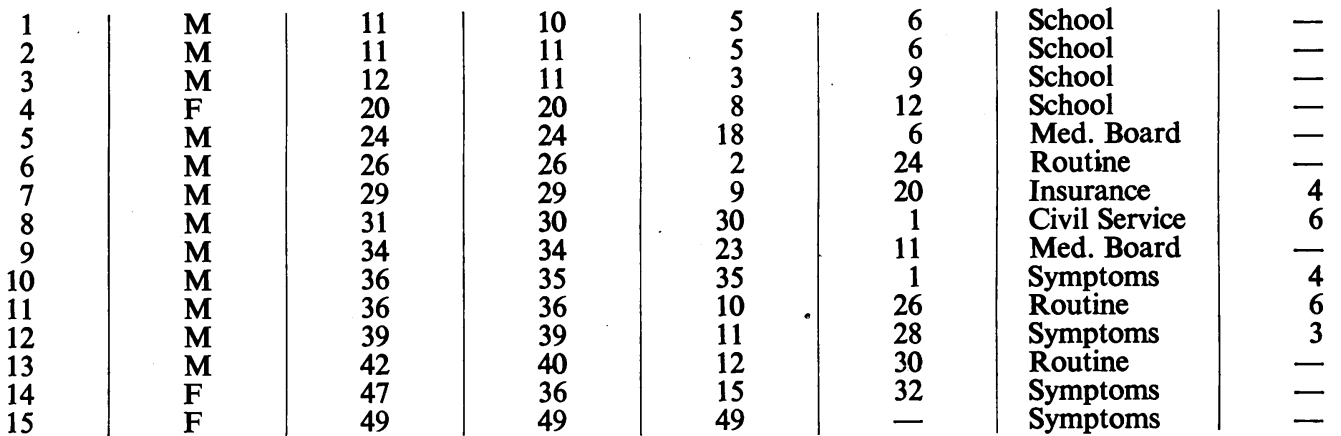

Cases from the records

\begin{tabular}{|c|c|c|c|c|c|c|c|}
\hline $\begin{array}{l}16 \\
17 \\
18 \\
19 \\
20 \\
21 \\
22 \\
23 \\
24 \\
25 \\
26 \\
27\end{array}$ & $\begin{array}{l}\mathbf{M} \\
\mathbf{M} \\
\mathbf{F} \\
\mathbf{F} \\
\mathbf{M} \\
\mathbf{F} \\
\mathbf{M} \\
\mathbf{M} \\
\mathbf{M} \\
\mathbf{F} \\
\mathbf{M} \\
\mathbf{M}\end{array}$ & $\begin{array}{l}= \\
= \\
= \\
= \\
= \\
= \\
=\end{array}$ & $\begin{array}{r}5 \\
11 \\
23 \\
25 \\
25 \\
26 \\
28 \\
31 \\
39 \\
42 \\
47 \\
48\end{array}$ & $\begin{array}{c}\text { Birth } \\
5 \\
? \\
5 \\
12 \\
21 \\
10 \\
29 \\
39 \\
6 \\
47 \\
39\end{array}$ & $\begin{array}{r}5 \\
6 \\
? \\
20 \\
13 \\
5 \\
18 \\
2 \\
36 \\
\frac{9}{9}\end{array}$ & $\begin{array}{c}\bar{Z} \\
\bar{Z} \\
\bar{Z} \\
\text { Symptoms } \\
\text { Symptoms } \\
\text { Symptoms } \\
\text { Symptoms }\end{array}$ & $\begin{array}{l}= \\
= \\
= \\
= \\
= \\
= \\
=\end{array}$ \\
\hline
\end{tabular}

TABLE II

Physical Signs in Pure Aortic Stenosis

\begin{tabular}{|c|c|c|c|c|}
\hline Case No. & $\begin{array}{l}\text { Character of } \\
\text { cardiac impulse* }\end{array}$ & $\begin{array}{l}\text { Aortic Systolic } \\
\text { thrill }\end{array}$ & $\begin{array}{l}\text { Character of } \\
\text { second sound }\end{array}$ & Blood pressure \\
\hline $\begin{array}{r}1 \\
2 \\
3 \\
4 \\
5 \\
6 \\
7 \\
8 \\
9 \\
10 \\
11 \\
12 \\
13 \\
14 \\
15\end{array}$ & $\begin{array}{l}\text { Forcible } \\
\text { Forcible } \\
\text { Normal } \\
\text { Forcible } \\
\text { Normal } \\
\text { Normal } \\
\text { Normal } \\
\text { Normal } \\
\text { Normal } \\
\text { Normal } \\
\text { Normal } \\
\text { Normal } \\
\text { Not palpable } \\
\text { Heaving } \\
\text { Forcible }\end{array}$ & $\begin{array}{l}\text { Present } \\
\text { Present } \\
\text { Present } \\
\text { Present } \\
\text { Present } \\
\text { Present } \\
\text { Present } \\
\text { Faint } \\
\text { Present } \\
\text { Faint } \\
\text { Present } \\
\text { Faint } \\
\text { Faint } \\
\text { Faint } \\
\text { Present }\end{array}$ & $\begin{array}{l}\text { Normal } \\
\text { Normal } \\
\text { Normal } \\
\text { Diminished } \\
\text { Normal } \\
\text { Diminished } \\
\text { Normal } \\
\text { Normal } \\
\text { Diminished } \\
\text { Normal } \\
\text { Normal } \\
\text { Normal } \\
\text { Normal } \\
\text { Diminished } \\
\text { Normal }\end{array}$ & $\begin{array}{l}100 / 75 \\
120 / 90 \\
90 / 70 \\
115 / 90 \\
135 / 110 \\
120 / 80 \\
135 / 95 \\
135 / 90 \\
130 / 90 \\
120 / 80 \\
130 / 90 \\
125 / 85 \\
130 / 80 \\
140 / 95 \\
140 / 90\end{array}$ \\
\hline
\end{tabular}

There was no evidence of a mitral lesion in any case.

* The position of the cardiac impulse was normal in all cases except in Case 14 where it was slightly displaced and perhaps in Case 13 where it was not felt. 
easily missed is not surprising. Naturally, there was always a corresponding harsh or rough systolic murmur heard in the aortic area and also in the mitral area, the intensity varying from case to case. The second heart sound, as heard in the aortic area, was normal in character in eleven and diminished in the remaining four, being easily audible in every case. After auscultation in various positions and after exertion, there was no evidence of mitral stenosis in any case, and this evidence would include not only the presystolic and mid-diastolic murmurs, but a loud first sound and the sound heard in early diastole variously ascribed to the third heart sound, the opening snap of the abnormal mitral valve, or splitting of the second heart sound. In the presence of aortic stenosis the systolic murmur in the mitral area must be attributed to the aortic valve and cannot be used as evidence to incriminate the mitral valve: the absence of a mid-diastolic murmur is of greater significance for there is no early diastolic murmur, so frequently well heard in the mitral area in aortic incompetence, to confuse the issue. The blood pressure showed no great departure from the normal.

\section{X-RAY FINDINGS}

Each of the fifteen cases was screened in the three orthodox positions. Summarizing, there would appear to be three important abnormalities, cardiac enlargement, prominence of the ascending aorta, and calcification of the aortic valve. Radiological evidence of cardiac enlargement was considered to be absent in only one case but in twelve others it was assessed as slight. In only two was it considered more than slight, and then only moderate. Enlargement was confined to the left ventricle in all and was judged more by increased convexity of the left ventricular border than by apparent increase in the surface area of the cardiac silhouette. The detection of lesser degrees of cardiac enlargement is a difficult radiological problem and in the group under discussion it is always so, for cardiac enlargement must be attributed rather to hypertrophy than dilatation so that the size-weight ratio is small compared for instance with corresponding degrees of aortic incompetence. More striking than the slight grade of cardiac enlargemènt, and easier to detect with certainty, was the increase in width of the aortic shadow, bearing in mind the comparative youth of this group of patients and the absence of hypertension. An example is given in Fig. 1. This was noted in all but one, to a greater or lesser degree, and was chiefly confined to the region of the ascending aorta. Calcification of the aortic valve was noted in eight of the fifteen cases. Finally, there was no radiological support for a diagnosis of mitral stenosis in any case.

\section{ELECTROCARDIOGRAPHIC FINDINGS}

The standard limb leads, and in addition multiple chest leads (CR or V) and the unipolar limb leads, were recorded in all cases. Of the fifteen studied twelve came within the normal limits, so that there was no evidence of left ventricular preponderance. The three showing left ventricular preponderance were Cases 4, 6, and 14. Case 4 showed a normal axis with high voltage $R$ waves and depression of the $\mathrm{R}-\mathrm{T}$ segment with deep inversion of $\mathrm{T}$ in the standard limb leads. There were similar changes in the chest leads facing the left ventricle, i.e. V5 and V7. The electrical axis was vertical in type as shown by the unipolar limb leads and the characteristic changes of left ventricular preponderance were seen in the lead facing the left ventricle, i.e. VF (Fig. 2A). Case 6 showed a normal axis in the orthodox leads accompanied by high voltage $\mathrm{R}$ waves followed by depression of the R-T-T complex in II and III. Similar changes were seen in V6 and VF, the electrical axis being vertical (Fig. 2B). Case 14 showed the orthodox type of left ventricular preponderance so that in the presence of left axis deviation there was depression of the $R-T$ segment with inversion of $T$ in leads I and II. Similar changes were present in leads V7 and VL, so that the electrical axis was horizontal (Fig. 2C). This case has been under observation since 1936 and in that year the axis was normal according to the orthodox leads with depression of $\mathrm{R}-\mathrm{T}$ and inversion of $\mathrm{T}$ in II and III. In the intervening period there has obviously been a change in position of the electrical axis from a vertical to a horizontal position. 


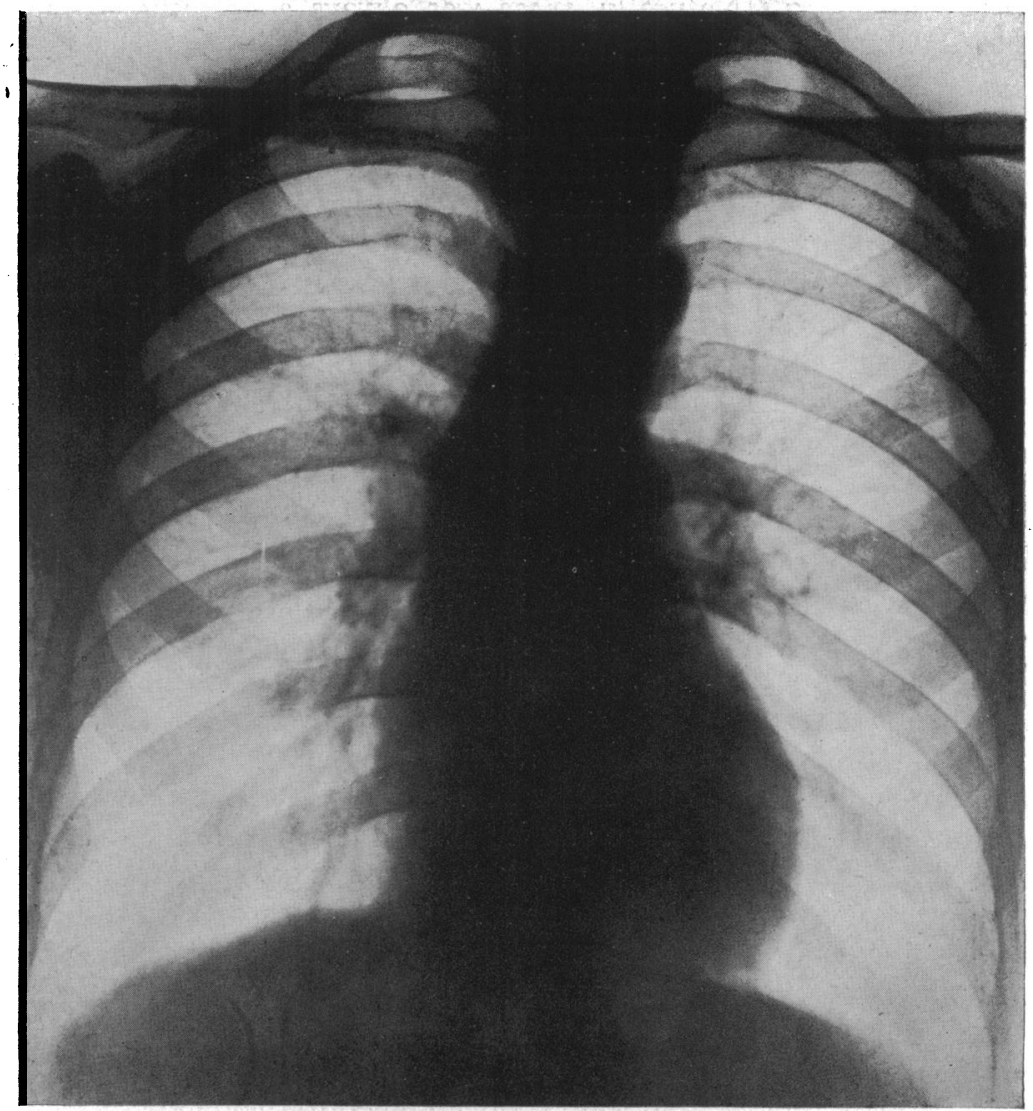

FIG. 1.-Case 8. Postero-anterior view showing prominence of the ascending aorta and increase in convexity of the left ventricular border. These features were more apparent on screening, which also revealed aortic valvular calcification.

Of the twelve cases that were considered normal four presented a vertical type electrical axis so that six cases in all belonged to this category, only one of which was in a child. One of these (Case 5) showed some right axis deviation in the standard limb leads with upright TII and deep inversion of TIII (Fig. 3).

Phonocardiographic findings. A phonocardiographic record using the electrocardiogram as the reference tracing was made in five cases and one is shown in Fig. 4. In four there was no evidence of a murmur in early diastole and in none was a presystolic or mid-diastolic murmur recorded, so that phonocardiographically the clinical condition of pure aortic stenosis was confirmed. Doubt has previously been cast upon the idea that aortic stenosis can be pure for the suggestion has been made that it will always be associated with a murmur in early diastole even though it is not always audible.

\section{Discussion: ETIOLOGY}

In such an age group the question naturally arises as to the part that rheumatic infection may or may not play in the causation of this type of aortic stenosis. The history in this series gives no support at all. As a contrast, in a series of forty-one cases of aortic stenosis and incompetence taken at random from the records of the National Heart Hospital twenty-four (60 per cent) gave a 
I

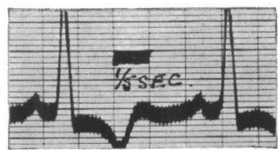

臬

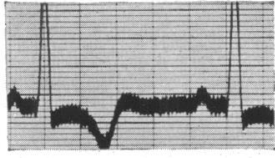

(5)

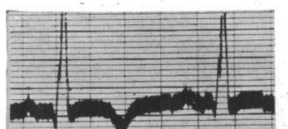

VI
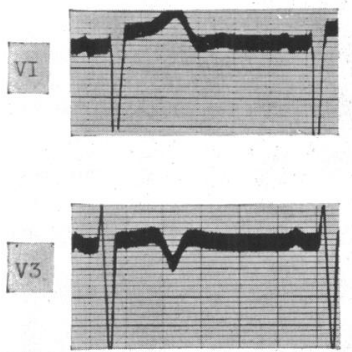

V4

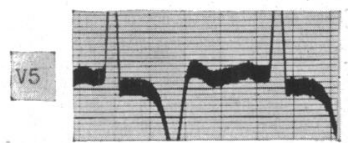

V6

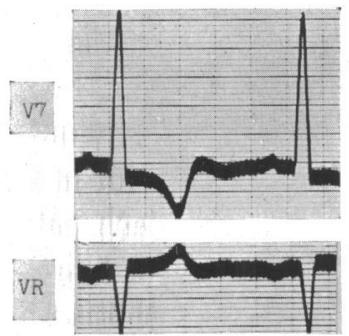

VL

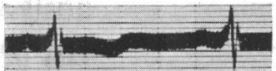

VF

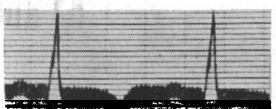

A
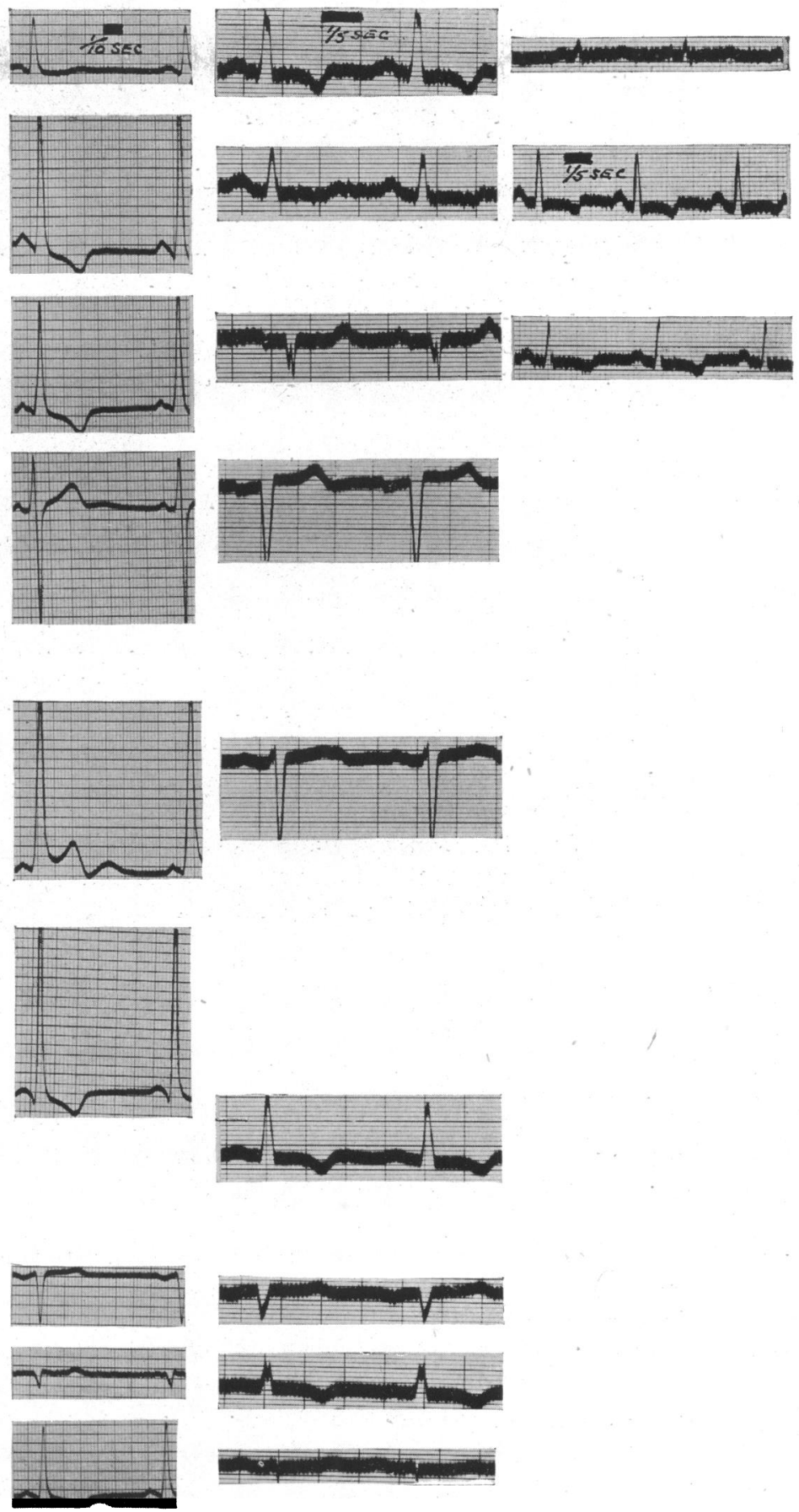

B

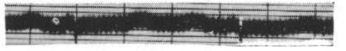

C

Fig. 2.-(A) Case 4. Left ventricular preponderance with high voltage normal axis in the orthodox leads. The chest leads confirm the ventricular preponderance, and the unipolar limb leads show that the electrical axis is vertical. (B). Case 6. Similar changes in Case 5; see Fig. 3. Here the T in lead I is isoelectric. (C) Case 14. In 1948, showing orthodox evidence of left ventricular preponderance, the unipolar limb leads confirming that the electrical axis is horizontal. The tracings taken in 1936 show that there has been a change in the axis which was then apparently of the vertical type. 

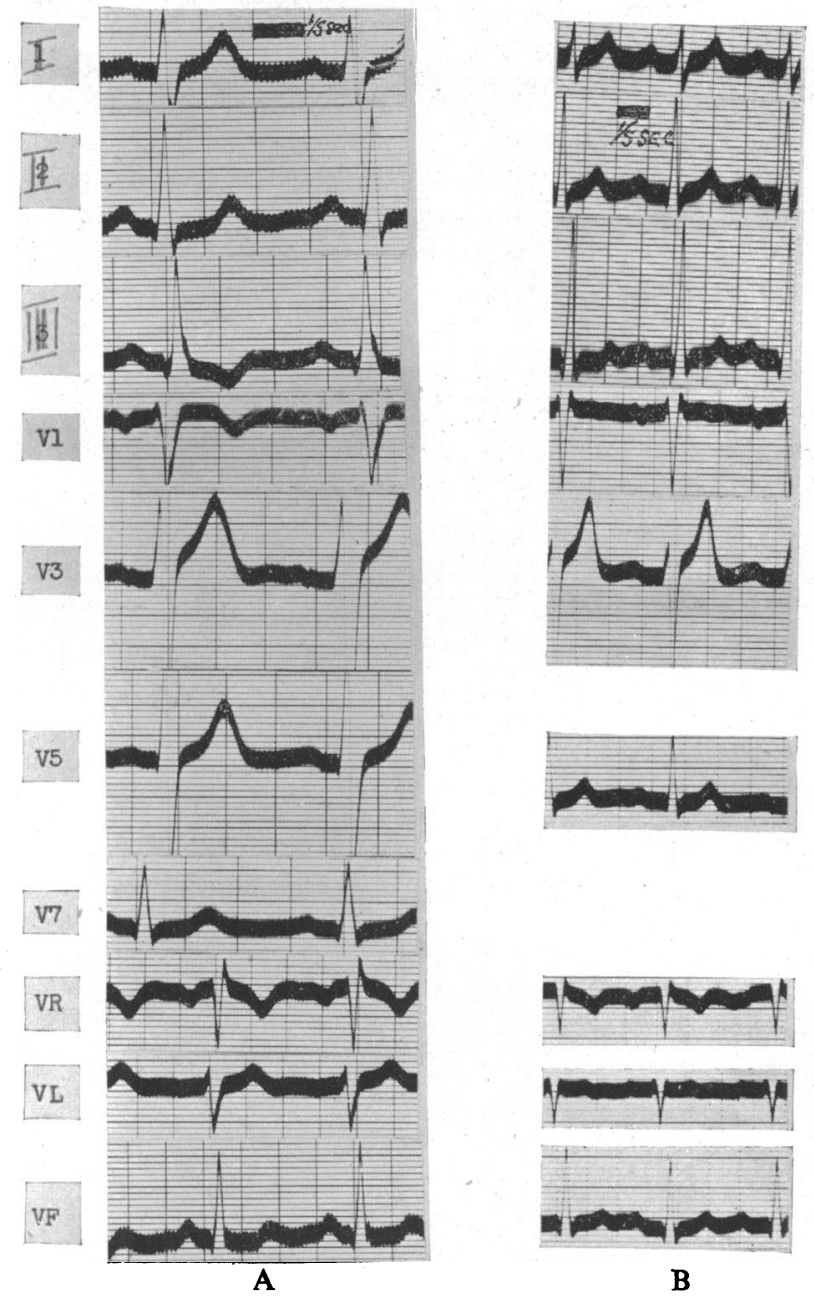

FIG. 3.-(A) Case 5. High-voltage right axis deviation with deep inversion of T III. The $\mathrm{T}$ over the right ventricle is tall and the $\mathrm{T}$ in VF is lower than the $\mathrm{T}$ in VL. The electrical axis is vertical as shown by the unipolar limb leads. Probably a normal curve. This patient had well marked calcification of the aortic valve. (B) Case 9. High-voltage right axis deviation with tall $\mathrm{T}$ over the right ventricle and vertical electrical axis. This patient had well marked calcification of the aortic valve.

rheumatic history, and in 104 cases of aortic incompetence and mitral stenosis, sixty-one (nearly 60 per cent) had a history of rheumatic infection. These percentages are minimal, for in some the history was not recorded. In addition to the absence of a rheumatic history, each patient was assessed for evidence of mitral stenosis including radiological examination and in none did this exist. For what it is worth the author cannot remember a case of pure aortic stenosis associated with mitral stenosis: and in studying the records of forty-one cases of aortic stenosis with mitral stenosis only three were found in which there was a possibility of the aortic stenosis being purethe notes being incomplete in each-the three patients in question were aged 57,62 and 65 years, so that they were outside the age limit under consideration.

So far the evidence in favour of a rheumatic basis for this type of aortic stenosis is completely lacking, but the argument has been used that rheumatism is responsible, the heart having almost escaped, except that the aortic valve alone has been "touched" and in the course of years has become increasingly calcified with resulting stenosis. Parkinson and Hartley (1946) discussed a series of 202 cases of aortic incompetence in service recruits, and though the majority were slight 


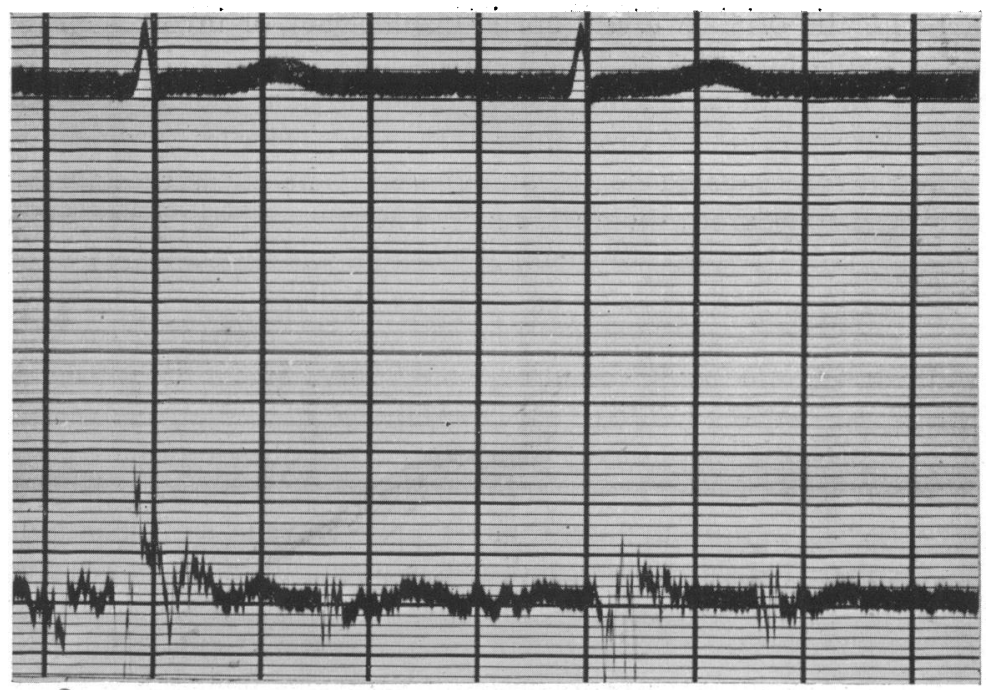

Fig. 4.-Case 3. Phonocardiogram showing murmur in systole but no early or other murmur in diastole.

in degree, ninety-eight (nearly 50 per cent) gave a rheumatic history. These cases in the main had no symptoms and no peripheral vascular signs, and surely result from an infection that has just "touched" the aortic valve: in spite of this a very high percentage gave a rheumatic history. A paper by Young (1944) lends unintentional support to a non-rheumatic basis: under the heading Congenital Sub-Aortic Stenosis he described ten cases picked up in 18,000 recruits, but it is clear from the clinical study that they presented the same clinical picture as those described in this paper, with no history of rheumatic infection and no evidence of mitral stenosis. Less than forty proven cases of sub-aortic stenosis have been reported, and this fact, coupled with the identical physical signs, supports the probability that all Young's cases were examples of pure aortic stenosis. If this be so, he misinterpreted the physical signs, so that here is another series of pure aortic stenosis without any history of rheumatic infection and no evidence of a mitral lesion. It is reasonable to assume that had others with the same signs presented with a history of rheumatic infection or evidence of a mitral lesion the non-rheumatic cases would not have been described as examples of sub-aortic stenosis.

Perhaps the strongest support for a rheumatic basis comes from the recent monograph of Karsner and Koletsky (1947) who conclude that calcific aortic stenosis is always of rheumatic origin. They investigated 200 cases coming to autopsy and their results show that with only rare exceptions, calcific disease of the aortic valve is the result of rheumatic cardiac disease. Of the 200 cases, four could not be shown to be rheumatic. The type of aortic stenosis described in this paper is certainly uncommon though it is not rare, and its incidence might well be covered by the 2 per cent of cases that Karsner and Koletsky failed to demonstrate to be rheumatic. It has also been suggested by Hall and Anderson (1943) that the incidence of rheumatic fever in the human race is comparable to that of tuberculosis and infantile paralysis. Should this be so, then the value of microscopy in the proof of valvular disease being of rheumatic origin will be diminished considerably and even a greater percentage of cases of aortic stenosis may be non-rheumatic than shown by Karsner and Koletsky, who relied largely upon microscopic findings for their results.

Gallavardin, in his three clinical papers, held strongly to the view that this group is non-rheumatic; he described fifty cases and considered that they followed a non-specific inflammatory condition resulting in chronic endocarditis acquired in infancy or early adult life. He also stated that rheumatic aortic stenosis will always be accompanied by some degree of incompetence. This opinion is shared more recently by Taussig (1947), who states that " the insidious development of 
aortic stenosis of rheumatic origin without aortic insufficiency or involvement of the mitral valve is so rare that it is virtually non-existent."

To sum up, the evidence is in favour of this type of aortic stenosis being of non-rheumatic origin, though there is no autopsy evidence to support this view. The lesion is benign, allowing gross calcification to occur before causing death, and probably in the later stages incompetence will occur, as a result of increasing deformity of the cusps. Microscopically, at this stage, it is likely that the valve is indistinguishable from that of rheumatic origin, and unless investigated by a pathologist trained in this particular field, will certainly be regarded as rheumatic . The answer to this problem can only come from a "follow-up" confined to this type of case over many years to the autopsy room. Even then the most valuable information would only come if the subject died from accident or intercurrent disease, so that the lesion could be examined at a relatively early stage.

If this type of aortic stenosis is not of rheumatic origin the question of a congenital origin has to be considered. The diagnosis of sub-aortic stenosis is frequently put forward when this combination of physical signs occurs, as was done apparently by Young, and this is the combination of signs that theoretically might be expected when the condition is uncomplicated. Less than forty examples of this lesion have been confirmed at autopsy, so its rarity must be accepted and therefore it cannot be lightly diagnosed. Support for the view that sub-aortic stenosis does not lend itself to clinical recognition is met by approaching the problem from another angle and examining the records of reported cases and noting whether in fact they did present these signs. The details of sixteen of these cases have been abstracted and are set out in Table III. Of the sixteen cases there are twelve

TABLE III

Reported Cases of Sub-Aortic Stenosis

\begin{tabular}{|c|c|c|c|c|}
\hline Author & Age & Clinical diagnosis & Auscultatory signs & Autopsy findings \\
\hline Banks, 1857 & 34 & Aortic incompetence & Loud early diastolic murmur & $\begin{array}{l}\text { Aortic valve thickened; } \\
\text { cribriform }\end{array}$ \\
\hline Lindman, 1880 & 19 & Coarctation of aorta & $\begin{array}{l}\text { Aortic S. thrill and mitral } \\
\text { M.D.M. }\end{array}$ & Aortic valve normal \\
\hline Moore, 1883 & 18 & 一 & IV.D.10. & $\begin{array}{l}\text { Aortic aneurysm, aortic } \\
\text { valve normal }\end{array}$ \\
\hline Trevor, 1901 & 9 & - & - & Mitral stenosis \\
\hline Smart, 1904 & 17 & Aortic incompetence & Loud lung D.M. & Aortic and mitral stenosis \\
\hline Shennan, 1905 & 19 & Aortic stenosis & A.S. thrill and murmur & Aortic stenosis \\
\hline $\begin{array}{l}\text { Thursfield and Scott, } \\
1913\end{array}$ & 14 & Ventricular septal defect & Loud long Aortic S.M. & Aortic stenosis \\
\hline $\begin{array}{l}\text { Lemierre and Ber- } \\
\text { nard, } 1925\end{array}$ & 18 & $\begin{array}{l}\text { Aortic stenosis } \\
\text { Mitral stenosis }\end{array}$ & $\begin{array}{l}\text { Aortic and mitral S. thrill } \\
\text { and murmur P.S.M. } \\
\text { M.D.M. }\end{array}$ & Aortic and mitral stenosis \\
\hline Enzer, 1927 & 40 & Mitral incompetence & M.S. thrill and murmur & Aortic stenosis \\
\hline $\begin{array}{l}\text { Sternberg, } 1930 \\
\text { Sternberg, } 1930\end{array}$ & $\begin{array}{l}27 \\
77\end{array}$ & Aortic stenosis & - & Aortic valve normal \\
\hline $\begin{array}{l}\text { Stewart and Bellet, } \\
1934 \text {. }\end{array}$ & 26 & - & Mitral S. murmur & Coarctation of aorta \\
\hline $\begin{array}{l}\text { Wiglesworth, } 1937 \\
\text { Dormans, } 1939\end{array}$ & $\begin{array}{r}8 \\
16\end{array}$ & Cong. morbis cordis & $\begin{array}{l}\text { Mitral S. thrill and murmur } \\
\text { Systolic murmur }\end{array}$ & $\begin{array}{l}\text { Aortic stenosis } \\
\text { Aortic stenosis }\end{array}$ \\
\hline $\begin{array}{l}\text { Mason and Hunter, } \\
1943\end{array}$ & 27 & $\begin{array}{l}\text { Aortic stenosis (calcific) } \\
\text { Sub-aortic stenosis }\end{array}$ & $\begin{array}{l}\text { Aortic S. thrill and murmur } \\
\text { A2 }\end{array}$ & Aortic stenosis \\
\hline $\begin{array}{l}\text { Walsh, Connerty } \\
\text { and White, } 1945\end{array}$ & 27 & $\begin{array}{l}\text { Aortic stenosis and incom- } \\
\text { petence }\end{array}$ & $\begin{array}{l}\text { Loud rough aortic } S \text {. thrill } \\
\text { and murmur blowing } \\
\text { D.M. A2 dim. }\end{array}$ & Aortic stenosis \\
\hline
\end{tabular}

in which the auscultatory signs are given in some detail and these do not agree with theoretical expectation as in only two cases was the lesion an isolated one. In one of these a mid-diastolic murmur was recorded and the physical signs were not mentioned in the account of the other. In only five cases was the aortic valve apparently normal, so that in eleven, aortic valvular stenosis of varying degree was noted. Mason's case was diagnosed in life because of the clear-cut second 
sound, absence of an aortic diastolic murmur, and evidence of aortic obstruction. As he at the same time diagnosed " calcific (probably) aortic stenosis," it is difficult to follow his reasoning that the subvalvular lesion was also present. It is a diagnosis not uncommonly offered, and rare though it is, will sooner or later prove to be correct. It would seem reasonable to assume that the condition cannot be recognized in life and that a more accurate diagnosis than aortic valvular stenosis is not possible in the present state of knowledge. When it does occur the chance of it presenting the signs given by the group of cases described above is small and it must be assumed in practice that all such cases have aortic valvular stenosis.

There are other possibilities of a congenital origin for this type of case. Koletsky (1941) has shown that a congenitally bicuspid valve may in the course of years undergo calcification; at the same time he regards this lesion as the most common single congenital cardiac anomaly. This might be expected to give rise to stenosis of varying degree. True congenital aortic stenosis is a well recognized though infrequent lesion, but can only be diagnosed with confidence when the characteristic signs are detected within the first three years of life. Does not the possibility exist of slighter degrees of this condition giving rise to no signs at birth or an early age, until later calcification takes place and results in stenosis? Finally, there is no knowledge of what may happen to a fenestrated aortic valve and whether it may become calcified. If any of these congenital possibilities exist it is likely that when death occurs, the precipitating cause will no longer be apparent because of extensive calcification and deformity.

Apart from these considerations it has been suggested that healed bacterial endocarditis may explain a diagnosis of aortic stenosis of non-rheumatic origin. In these days of penicillin this becomes increasingly possible, but certainly does not apply to the cases under discussion. Such a view has been described by Willius and Dry (1939) as fantastic.

Finally, there is the view of Gallavardin as described above, but all these theories remain theories in the absence of post-mortem evidence in this type of case.

\section{Clinical Signs}

It has been traditionally taught that there are five abnormal physical signs to be sought before a diagnosis of aortic stenosis is justified. These are $(a)$ a systolic thrill in the aortic area, $(b)$ a long harsh or rough systolic murmur in the aortic area, $(c)$ diminution or absence of the second sound in the same area, $(d)$ evidence of left ventricular hypertrophy, and $(e)$ alteration in the character of the peripheral pulse wave, i.e. pulsus bisferiens or pulsus anacroticus. Because of too strict adherence to some or all of these criteria lies the probable reason why aortic stenosis is so frequently missed in diagnosis, a fact that has been pointed out by several writers and more particularly by Karsner and Koletsky. Excluding examination of the peripheral pulse wave (which clinically is so much a matter of opinion) the present group of cases in the main only exhibited two of these signs, i.e. the thrill and murmur, and the former was often difficult to elicit. The most constant and reliable sign, therefore, was the long harsh or rough systolic murmur in the aortic area. It is interesting to recall that both Willius (1939) and White (1944) regard a murmur of maximal intensity in the aortic area as almost always organic and due to disease of the aorta or aortic valve. In this connection Willius states: "I have had the opportunity to examine numerous patients in whom the detection of an aortic systolic murmur many years before had been disregarded and said to be of no significance. Among these patients were some veterans of the World War who were unequivocally accepted for active service in spite of the recognition of an aortic systolic murmur. The ensuing years proved my contention of the significance of this murmur as the patients under discussion all presented well marked calcareous stenosis of the aortic valve at the time of my examination 15-20 years later." The cases described by Willius are similar to the group described in this paper and of the five patients who served for long periods on active military service four have been shown to have a calcified aortic valve.

The importance of diminution or absence of the aortic second sound in aortic stenosis has for 
long been stressed. Dry and Willius (1939) regard the preservation of the second sound in this condition as indicative of the dynamic function of the cusps and as an indication therefore that the degree of stenosis is mild or moderate. They also believe that in aortic stenosis the second sound in the aortic area may be normal as do McGinn and White (1934) and others. In this series the second sound was considered to be normal in eleven of the fifteen cases and in six of these the valve was radiologically calcified. Not only may the aortic second sound be normal in aortic stenosis but it may be normal even in the presence of radiological calcification. In these cases it is reasonable to believe that the deposit of calcium must be in the neighbourhood of the aortic valve ring, leaving the cusps comparatively healthy. The intensity of the second sound is probably of value in assessing the degree of aortic stenosis and it would seem that this may be fairly considerable in the presence of a normal second sound.

Clinically, the size of the heart may be estimated by two factors: the position of the cardiac impulse and its character. In this series of cases, in the majority, both the position of the impulse and its character were within normal limits.

\section{RADIOLOGY}

Only two of these fifteen cases showed conclusive evidence of left ventricular enlargement. In one there was no such evidence and in the remainder it was considered to be slight. When radiological evidence for ventricular hypertrophy is slight it becomes very much a matter of opinion whether it is present or not. When cases in which an aortic systolic murmur is the principal sign are being assessed, such equivocal evidence in support of a diagnosis of aortic stenosis should be confirmed if possible by other and more reliable signs. Prominence of the ascending aorta was noted frequently in this series in the postero-anterior and left oblique views. This was often striking and was easier to assess with certainty than any change in the cardiac contour: there is good reason, therefore, to regard it as a sign of greater importance as it is easier to detect. The fact that the aorta immediately above a stenosed aortic valve is dilated would not appear to be commonly realized and is not discussed as an aid to diagnosis in such cases. Perhaps this is because the majority of cases of aortic stenosis are not pure and any prominence in the ascending aorta is attributed to the presence of incompetence. It should not be surprising that the ascending aorta is dilated in such circumstances, as the pulmonary artery is frequently so in the corresponding condition of pure pulmonary stenosis, and it is reasonable to assume that the mechanism is the same in both types of case. If an artery be partially constricted, dilatation of the vessel will occur immediately beyond the stricture and it is likely that the post-stenotic dilation in aortic and pulmonary stenosis is related to this. In aortic stenosis there is the additional factor that the aorta is not straight, so that the stream of blood passing through the stenosed valve at a high velocity is likely to impinge upon the right wall of the ascending aorta, opposite the aortic valve, causing it to bulge in systole. On this theory it is likely that the dilatation of the ascending aorta in pure aortic stenosis is directly proportional to the degree of stenosis. There is some pathological support for this view. Hall and Ichioka (1940) have reported " impingement plaques " of the aorta in severe aortic stenosis, the aorta being otherwise unusually healthy considering the age of the subject. The plaque is an atheromatous lesion situated in the median-posterior aspect of the ascending aorta $6-8 \mathrm{~cm}$. long and $1-1.5 \mathrm{~mm}$. wide. Although these plaques do not seem to be reported by others, they suggest that extra stress is taken by that part of the aorta diametrically opposite the aortic valve.

Intra-cardiac calcification in the neighbourhood of the aortic valve was present in eight of the fifteen cases and the search for this may therefore be helpful and important. In seven, the presence of cardiac enlargement was a matter of opinion, whereas there could be no doubt about the valvular calcification. It is the dynamic movement of the dancing intra-cardiac shadows that is convincing in the recognition of this condition, so that the radioscopy is more helpful than radiography. Another sign was sustained pulsation of the aorta, but this could only be detected in a small number of the more severe cases where the condition was easily recognized by other means'. 
In the diagnosis of pure aortic stenosis the best radiological evidence is undue prominence of the ascending aorta and calcification of the aortic valve.

\section{ELECTROCARDIOGRAPHY}

Of the fifteen patients studied, eleven were electrocardiographically normal. From a prognostic point of view this is not surprising and is in accordance with the freedom from symptoms which these patients enjoy.

In six cases a vertical electrical axis was present, and five of these were adults. In the standard leads there was a normal axis or right axis deviation and the true axis was shown by the use of the unipolar limb leads. There was nothing in the body build of these patients to make one expect this, but it seems to be common in aortic valvular disease. This cannot support the belief that mitral stenosis was present, for right axis deviation is not inconsistent with left ventricular hypertrophy, as has been shown by the work of Wilson and Goldberger. The pattern of left ventricular preponderance is then altered: for whereas with the orthodox type (with left axis deviation) depression of the R-T-T complex begins and is greatest in lead I; with the electrical axis of the vertical type (with normal or right axis deviation in the standard leads) $\mathrm{R}-\mathrm{T}-\mathrm{T}$ depression may be present in all three leads or may begin and be most marked in lead III. Examples are shown in Cases 4 and 6 as described above, and Case 14 is an example of the common or orthodox type of left ventricular preponderance with left axis deviation and formerly (in 1936) was an example of the less common type, there being a change of the position of the electrical axis in the intervening years.

\section{SUMMARY}

Fifteen patients with pure aortic stenosis, all under the age of 50 years, are described, together with a review of the history of a further twelve patients taken from hospital records.

The ætiology is discussed and there is general agreement with the conclusions of Gallavardin that rheumatic infection cannot be the responsible agent. Other possible causes are discussed but there can be no final answer in the absence of autopsy investigation. Because of the physical signs presented in this group the diagnosis of sub-aortic stenosis is often advanced, but cannot be substantiated here; it is suggested that this condition cannot be recognized in life though it is possible that angiocardiography may assist in future. A long-term investigation confined to this type of case is necessary before the answer to this ætiological problem is obtained.

The physical signs are briefly discussed and the combination, characterized as it is mainly by a systolic murmur in the aortic area, is one that can be and is easily overlooked. The second sound in the aortic area is often normal, even in the presence of calcification of the aortic valve.

The radiological evidence shows that cardiac enlargement is generally slight, and therefore not convincing to all. In the assessment of cases presenting with an aortic systolic murmur, the importance of prominence of the ascending aorta and calcification of the aortic valve in support of a diagnosis of aortic stenosis is stressed.

Electrocardiograms showed evidence of left ventricular preponderance in only four of the fifteen cases studied so that this could not be relied upon to assist in the diagnosis. Of these, three showed a vertical type electrical axis and because of this the evidence in support of ventricular preponderance was not of the orthodox kind. There were six cases that showed a vertical electrical axis and it is believed that this is not uncommon in aortic valvular disease.

Phonocardiographic evidence showed that aortic stenosis can be pure.

With no symptoms, minimal cardiac enlargement, and normal electrocardiographic tracings, it is likely that many of these patients will survive to the age when atherosclerotic aortic stenosis becomes a consideration in diagnosis. Many of these were discovered by accident, and had no symptoms. Had this fortuitous happening not occurred, the diagnosis might have had to wait for 
the development of symptoms, which might well have been past the age of 50 years. The relationship between this type of aortic stenosis and the calcific aortic stenosis of elderly people may be a close one.

I wish to thank the members of the Staff of the National Heart Hospital and Institute of Cardiology for permission to study patients under their care; without their help and encouragement this paper would not have been possible. I also wish to thank Dr. William Evans for his permission to reproduce the phonocardiogram which is one of several that he kindly recorded for me.

\section{REFERENCES}

Banks, J. T. (1857). Dublin Hosp. Gaz., 4, 33.

Dormanns, E. (1939). Beitr. Path. Anat., 103, 235.

Dry, T. J. and Willius, F. A. (1939). Amer. Heart J., 17, 138.

Enzer, N. (1927). Arch. Path., 4, 966.

Gallavardin, L. (1909). Lyon Med., 112, 189.

(1921). Presse. Med., 29i, 224.

(1936). J. Med. Lyon, 17, 593.

Hall, E. M. and Anderson, L. R. (1943). Amer. Heart J., 25, 64.

and Ichioka, T. (1940). Amer. J. Path., 16, 761.

Karsner, H. T. and Koletsky, S. (1947). Calcific Disease of the Aortic Valve. Philadelphia.

Koletsky, S. (1941). Arch. intern. Med., 67, 129.

Lemierre, A. and Bernard, E. (1925). Gaz. Hosp., Paris, 98, 325.

Lindman, J. H. (1880). Dtsch. Arch. Klin. Med., 25, 510.

Mason, D. G. and Hunter, W. C. (1942). Amer. J. Path., 18, 343.

McGinn, S. and White, P. D. (1934). Amer. J. Med. Sci., 188, 1.

Monckeberg, J. G. (1904). Virchows Arch., 146, 472.

Moore, N. (1883). Trans. Path. Soc. Lond., 34, 29.

Parkinson, J. and Hartley, R. (1946). Brit. Heart J., 8, 212.

Shennan, T. (1905). Lancet, 1, 21.

Smart, A. (1904). Ibid., 2, 1417.

Sternberg, C. (1930). Verh. dtsch. path. Ges., 25, 238.

Stewart, H. L. and Bellet, S. (1933-34). Amer. Heart J., 9, 533.

Taussig, H. B. (1947). Congenital Malformation of the Heart. New York.

Thursfield, H. and Scott, H. W. (1913). Brit. J. Child. Dis., 10, 104.

Trevor, R. S. (1901-2). J. Anat. Lond., 36, 44.

Walsh, B. J., Connerty, H. V. and White, P. D. (1943). Amer. Heart J., 25, 837.

Wiglesworth, F. W. (1937). J. Tech. Meth., 17, 102.

Willius, F. A. (1939). Proc. Mayo Clin., 14, 671. and Dry, T. J. (1939). Ibid., 14, 245.

White, P. D. (1944). Heart Disease. New York. 3rd edition.

Young, D. (1944). Amer. Heart J., 28, 440. 